\title{
Parameters of the constitutive model of geomaterials formed with the use of DSM dry technology
}

\author{
Klaudia Jendrysik ${ }^{1, *}$, Michat Pachnicz ${ }^{1}$, and Pawet Dudziński ${ }^{2}$ \\ ${ }^{1}$ Wroclaw University of Science and Technology, Wyb. Wyspiańskiego 27, 50-370 Wrocław, Poland \\ ${ }^{2}$ MENARD Polska Sp. z o.o. ul. Powązkowska 44c, 01-797 Warsaw, Poland
}

\begin{abstract}
Numerical modelling of geomaterials is always complex due to the variability of parameters within the soil massif (created in the natural geological processes) and the orthotropy caused by this. In the case of the soil substrate modification with the use of hydraulic binders, this issue is complicated even more due to the fact the degree of mixing can be differentiated for various areas, while in the dry mixing technology, it is additionally differentiated with the depth of consolidation stress. Additional factor that makes it difficult to predict the behaviour of stabilised soil is the possible content of organic parts. Due to the development of substrate reinforcement technology, as well as the growing market for such works, a need emerged to provide parameters of the numerical model for various materials or, at least, to provide a method for reverse analysis on the basis of available data. This paper presents an example of calibration of the selected numerical model (through parameter selection of this model) based on the conducted examinations of cubic sample in the conditions of uniaxial compression. The results of laboratory tests, reverse analysis in the numerical model with a pre-selected strength hypothesis and finally, the recommendations for selection of the model in calculations of real structure on a reinforced substrate, are demonstrated.
\end{abstract}

\section{Introduction - scope of the work}

The main purpose of this work is the secondary determination of parameters of a dry-mixed soil-cement material $[1,2]$. Such material is obtained as a result of mixing the binder with the native soil without additional provision of water. Changes in the chemical composition are introduced by mixing in the cements, ashes, lime or bituminous grout. The multitude of binders, which are available on the market, as well as the variety of soil conditions that we can encounter, result in the fact that the quantity of materials, which can be obtained, may be considered to be unlimited. Despite the widely available computer programs that operate on the principle of the finite element method, a challenge encountered by the designer is associated with the selection of material parameters in the process of design. The conducted calculations are limited by the knowledge concerning initial values of the material.

\footnotetext{
* Corresponding author: 216952@student.pwr.edu.pl
} 
The numerical model requires the introduction of unambiguous values, while in the case of soil-cement materials, it is even difficult to obtain any approximate data. The contractor companies that reinforce the substrates do not publish the results of their research, thus in relation to the strength, it is only possible to rely on research conducted on test batches. However, it is necessary to remember that this is an upper estimation of the strength of a given material, which is only possible to obtain in laboratory conditions.

The examples of such technological design procedures were provided in the works conducted within the research program at the Wroctaw University of Science and Technology. The tests were conducted for two various technologies: wet mixing with the use of cement binder [3] and ashes [4], as well as dry mixing [5, 6]. The results obtained in the cited works cannot be directly compared due to the fact that different soil and binder were used. However, it is noticeable that the wet mixing technology provides several times more beneficial parameters than in the case of dry mixing. Thus, it is recommended for a good reason to use dry mixing technology only in the case of soils with a minimum moisture content of $60 \%$.

Not only the mixing method, but also the used binder has impact on the obtained strengths. In the case of wet mixing of soils [3] with the content of organic part approx. $5.5 \%$, it was noticed that much better results are obtained by using cement without the addition of ash. Moreover, it is recommended to use mixtures with the addition of blast furnace slags in the case of organic soils. It is necessary to remember that different types of cement give different strengths to individual soils [7, 8]. It has been proven that the metallurgical cement works in the best manner in the sandy soil, while in the case of clays and loams, it is good to use quicklime or lime with cement.

After addition of a binder, there can be observed an increase in strength in each type of soil, however the content of organic parts in the native soil has undoubtedly a negative impact on the strength of the soil-cement material. Soils with the organic content above $6 \%$ are considered difficult to reinforce. Deep Soil Mixing dry and Mass Stabilization dry technologies belong to the group of few technologies, which are possible to use and which are profitable in soils with a large part of organics, unfortunately they still are rarely chosen in Poland. Certainly, one of the reasons is the large number of hazards and enforcement restrictions $[9,10]$. However, it is necessary to remember that despite the disadvantages, dry technologies also have many advantages - they provide the possibility of working at low temperatures, they do not generate spoil and they are comparatively cheap.

Discrepancy between the results obtained in individual studies proves that the test should be performed each time before proceeding with the design process [11]. Even small changes in the soil parameters, such as natural moisture content, content of organic part or cohesion, can cause to obtain different results [12]. Therefore, there is no single universal principle that a designer could follow during selection of parameters, thus the only possibility is to calibrate the numerical model for each case individually [13]. It should also be remembered that the soil subjected to the test is thoroughly mixed, so its properties have become homogenised in some way. On the other hand, during stabilisation we are not able to provide such thorough mixing of the soil with the binder, and we encounter material that is not the same over the entire surface and depth, which further makes it difficult to properly select the parameters. It is especially important for large infrastructural projects, where the soil diversity imposes more sophisticated quality control procedures $[14,15]$.

\section{Materials and Methods}

In the scope of determining parameters of the constitutive model, it is important to find a criterion which describes the behaviour of tested material in the best possible way. 
The selected hypothesis reflects the idealized creation and often through the implemented assumptions, it does not take into account all phenomena occurring in the material. It may turn out that each of the hypotheses closely presents one particular feature. The characteristics of four selected strength criteria are presented below.

\subsection{Coulomb - Mohr}

The Coulomb - Mohr model is the basic strength hypothesis, which is the starting model for all more complex models [16]. In order to use this hypothesis, it is necessary to define the strain modulus E, the Poisson's ratio $v$ and the parameters responsible for determining the plasticity condition of the soil material - internal friction angle $\phi$ and cohesion $c$. In the Coulomb-Mohr hypothesis, the plasticity area can be described with the use of the following equation (1):

$$
1 / 2\left(\sigma_{\max }-\sigma_{\min }\right)+1 / 2\left(\sigma_{\max }+\sigma_{\min }\right) \cdot \sin \phi-c \cdot \cos \phi=0
$$

$\sigma_{\max }, \sigma_{\min }-$ maximum, minimum stresses (negative compressive stresses)

$\phi$-internal friction angle, $c$ - cohesion

Individual functions of the equation (1) are called boundary functions and they outline a pyramid in the space of main stress components (Figure 1), which is based on an equilateral hexagonal with different angles. Due to the occurrence of sharp edges, the solution of such issue with the use of the finite element method can be troublesome.

\subsection{Drucker - Prager}

Similarly to the case of Coulomb - Mohr, the Drucker - Prager model also requires the strain module E, the Poisson's ratio $v$, internal friction angle $\phi$ and cohesion $c$, whereas the internal friction angle and cohesion are responsible for determining the condition of plasticity. The Drucker - Prager model modifies Coulomb - Mohr's theory and thanks to that, it gets rid of sharp edges in the area of plasticity. The image of this hypothesis consists of a cone (Figure 2) - inscribed into a hexagon and described on it. Thanks to the smooth edges, this model is often used in commercial programs. Moreover, it takes into account the isotropic reinforcement and weakening of the material. Unfortunately, the laboratory tests confirm that this model is not suitable for describing soils with high internal friction angles.

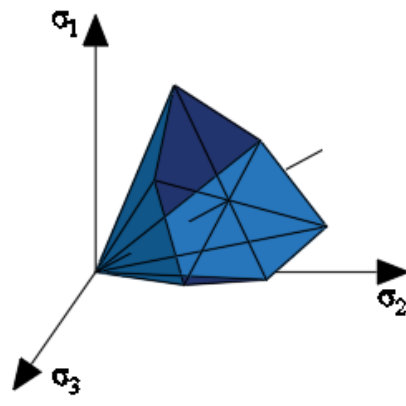

Fig. 1. Image of the Coulomb - Mohr hypothesis.

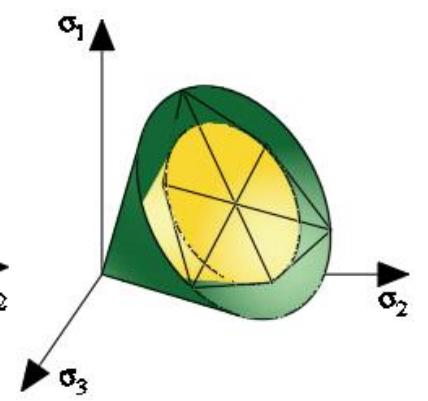

Fig. 2. Image of the Drucker - Prager hypothesis.

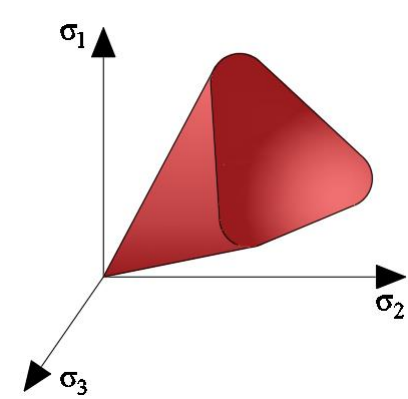

Fig. 3. Image of the Cam - Clay hypothesis. 


\subsection{Cam - Clay}

The Cam - Clay model is based on the Modified Cam - Clay model, which differ in the method of modelling in the supercritical area. The elastic - plastic part in both hypotheses is described with the following equation (2):

$$
q^{2}+M^{2} \cdot p^{\prime}\left(p^{\prime}-p^{\prime}\right)=0
$$

$q-$ stress intensity, $p_{c}{ }^{\prime}$ - preconsolidation pressure, $p^{\prime}$ - effective mean stress

$M$ - inclination of the critical state line in the invariant system $p, q$ (Figure 4)

Cam - Clay is a non-linear model, which very well reflects the real behaviour of the soil. The basic assumption consists of a logarithmic relationship between mean stress and porosity. Image of the hypothesis in the stress space consists of a triangle with rounded corners (Figure 3). In this case, it is necessary to obtain more information about the material: swelling inclination angle $\kappa$, inclination angle of the normal consolidation line $\lambda$, initial porosity index $e_{0}$, preconsolidation index OCR, cohesion $c$, internal friction angle $\phi$, internal friction angle at constant volume $\phi_{c v}$ and Poisson's ratio $v$.

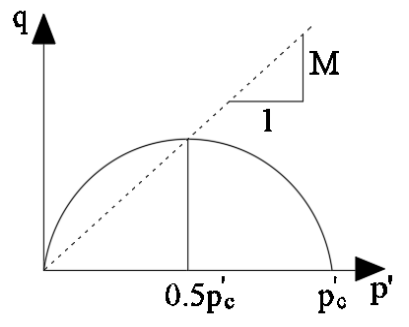

Fig. 4. Inclination of the critical state line.

\subsection{Hardening Soil}

Similarly to the previous hypotheses, the Hardening

Soil model belongs to the group of elastic - plastic models. It occurs in two versions Standard and Small. It gained its popularity due to the possibility to conduct advanced analyses and the mapping of [17]:

- density effect,

- impact of the load history,

- plastic flow,

- dependence of stiffness on the state of effective stresses,

- change in the volume during plastic flow,

- change in the soil stiffness.

\section{Results of laboratory tests}

This test was aimed at determining the compressive strength and parameters of the constitutive model of a soil-cement sample. In the future, the results may be used to model this material in computer programs, bearing in mind that this is the upper estimation of strength.

A sample was analyzed consisting of the mixture of soil and metallurgical cement CEM III/32.5 N. The soil was characterized by the content of organic part $6.61 \%$ and natural moisture content $48.83 \%$. It should be noted that both parameters do not meet the technological recommendations. Due to the high content of organics, this soil is considered to be a material difficult to reinforce, while the natural moisture content of the material is well below the recommended value typical for use in dry mixing. The binder content in the sample amounts to $172 \mathrm{~kg} / \mathrm{m}^{3}$. 
The cement was mixed with the soil in laboratory conditions with the use of an electric stirrer at a constant speed (Figure 5). The obtained batch was placed in a standardized mould, with the dimensions of $15 \times 15 \times 15 \mathrm{~cm}$, in four layers (Figure 6). Each layer was compacted under the pressure of $18 \mathrm{kPa}$. The top layer was cut in order to obtain the most even surface possible. The sample matured in the conditions of normal humidity at $18^{\circ} \mathrm{C}-$ $20^{\circ} \mathrm{C}$. After 28 days, the sample was destroyed in the machine intended for uniaxial compression (Figure 7, Figure 8).

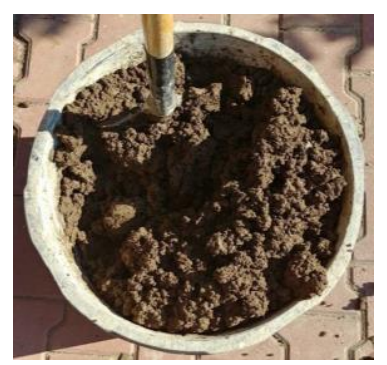

Fig. 5. Soil mixed with the binder.

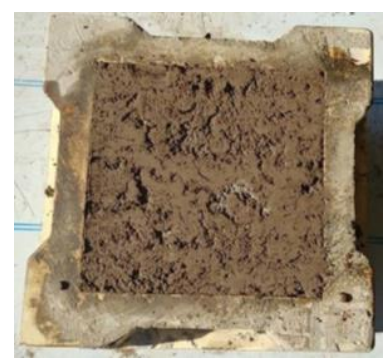

Fig. 6. Compacted sample in the mould.

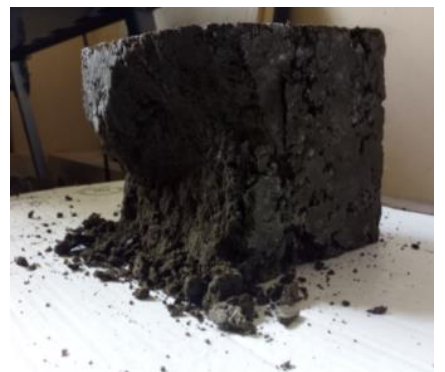

Fig. 7. Mechanism of destruction of soil-cement composite.

\subsection{Strength}

The value of displacement of the upper piston and the value of applied force were obtained from the universal testing machine. The piston moved at a constant speed. Strain of the material was determined using the following formula (3):

$$
\varepsilon=\Delta u / h \cdot 100 \%
$$

$\varepsilon$-strain, $\Delta u$-displacement of the piston, $h$-initial height of the sample and stress (4):

$$
\sigma=F / A
$$

$\sigma$-stress, $F$ - force, $A$ - surface area

The results are presented in the graph (Fig. 9). The sample strength of $R_{c}=0.346 \mathrm{MPa}$ was noted, with a simultaneous strain of $\varepsilon=2.74 \%$. 


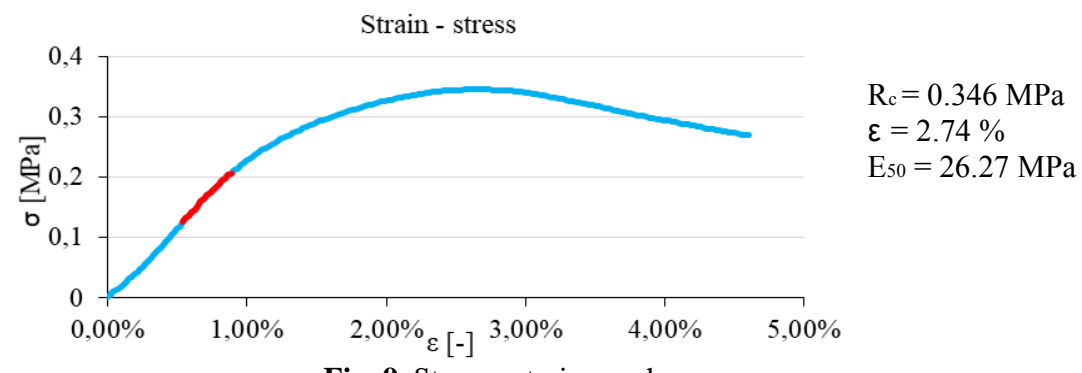

Fig. 9. Stress - strain graph.

\subsection{Strain module}

Due to behaviour of the material, the strain module was determined using a different method than it is usually used for concrete samples. In the case of soil-cement, it is determined in the area of $50 \%$ of the sample's compressive strength. In the graph (Fig. 9), the area of determining the module value is marked in red. The value of $E_{50}$ strain module amounts to $26.27 \mathrm{MPa}$.

\section{Description of the numerical model of compression test in the universal testing machine}

The numerical model of compression of the soil-cement sample was conducted in the ZSoil 2018 software. A cube with the dimension of $0.15 \times 0.15 \times 0.15 \mathrm{~m}$ was modelled. Due to the uncomplicated geometry, a rare mesh was selected $-3 \times 3$ elements. All three degrees of freedom of the nodes were blocked on the bottom and top surface of the model. The mapping of sample compression consists of the task of moving the upper support. The piston in the universal testing machine moved uniformly, thus while knowing duration of the test and strain of the material, a linear function of the support displacement was implemented. The analysis was carried out for the basic strength criterion of Coulomb Mohr and for Drucker - Prager. It was decided to choose these two hypotheses, because they are based on the same parameters, while the Drucker - Prager hypothesis is a modification of the Coulomb - Mohr hypothesis, which makes them comparable. In both cases, the material parameters were changed in iterative manner, such as: internal friction angle, cohesion and Poisson's ratio.

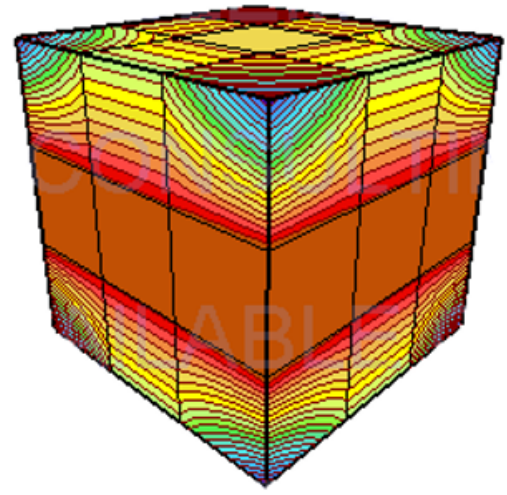

Fig. 10. Stress map according to the Coulomb - Mohr analysis.

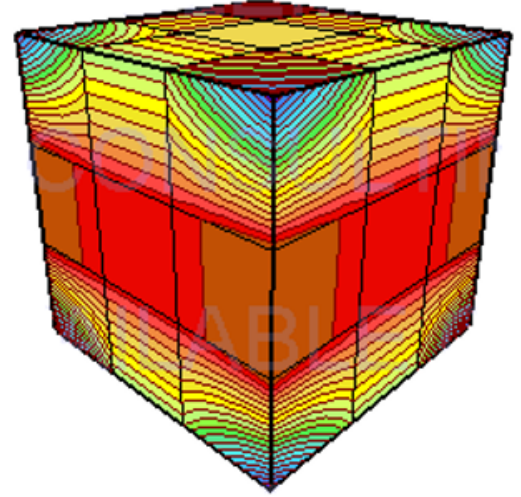

Fig. 11. Stress map according to the Drucker - Prager analysis.

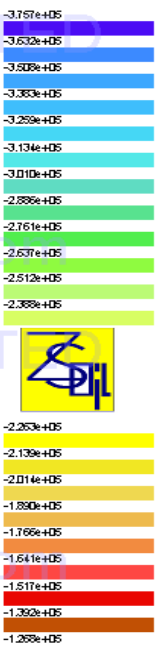


In the analysis according to Coulomb - Mohr, the following initial parameters were set: $c=32 \mathrm{kPa}, \phi=26^{\circ}, v=0.3$. For the Drucker - Prager criterion, the following input parameters were selected: $c=45 \mathrm{kPa}, \phi=33^{\circ}, v=0.3$. By accepting two material parameters as constants, the third was iterated in 10 steps. Below, there are value ranges presented, in which the individual material properties were changed:

Table 1. Parameters for Coulomb - Mohr criterion.

\begin{tabular}{|c|c|c|}
\hline Parameter & $\begin{array}{c}\text { Initial } \\
\text { value }\end{array}$ & Final value \\
\hline $\mathrm{c}$ & $22 \mathrm{kPa}$ & $42 \mathrm{kPa}$ \\
\hline$\phi$ & $21^{\circ}$ & $31^{\circ}$ \\
\hline$v$ & 0.10 & 0.49 \\
\hline
\end{tabular}

An envelope was created for each parameter, which allows to determine the maximum and minimum values of stress. The results of conducted iterations consist of graphs presented below (Figures 12 - 17), which were created in the Mathematica software.

\section{Results of numerical calculations in the context of tests in the universal testing machine}

\subsection{Coulomb - Mohr Hypothesis}

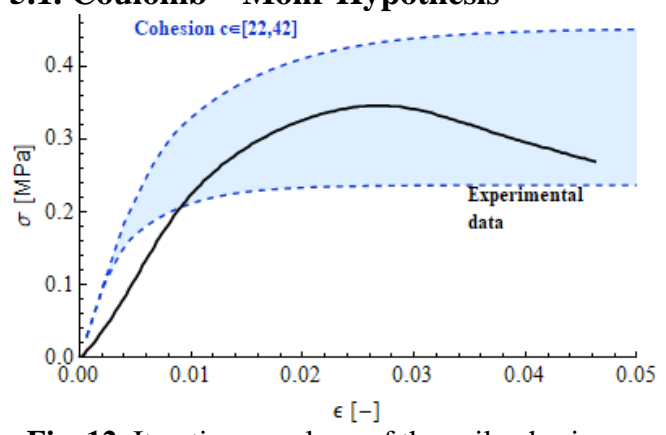

Fig. 12. Iteration envelope of the soil cohesion.

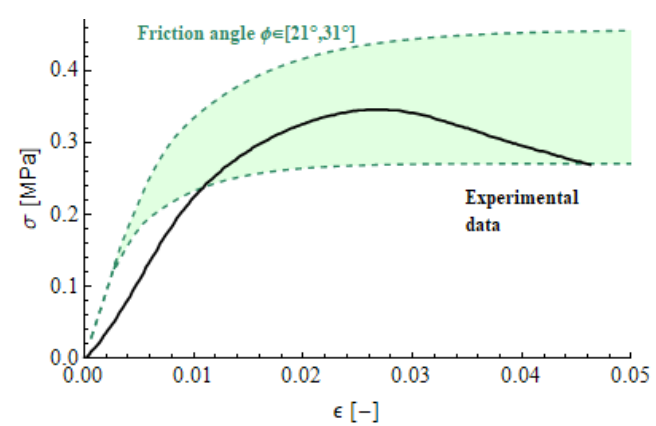

Fig. 13. Iteration envelope of the internal friction angle of the soil.

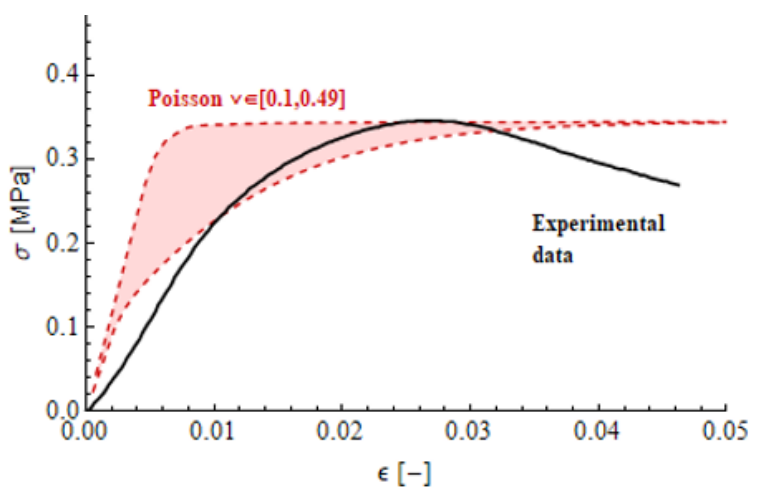

Fig. 14. Iteration envelope of the soil Poisson's ratio. 
It can be seen from the graphs in Figures 12-14 that strength parameters of the soilcement are within the assumed ranges. Thus, with the assumption of internal friction angle of $26^{\circ}$ and the Poisson's ratio of 0.3 , the cohesion of soil-cement is in the range of $22 \mathrm{kPa}-$ $42 \mathrm{kPa}$. On the other hand, for the cohesion of $32 \mathrm{kPa}$ and the Poisson's ratio of 0.3 , the friction angle value can be estimated to be in the range of $21^{\circ}-31^{\circ}$. It can be noticed that in both cases, the upper estimation provides much higher stress values than those obtained in the universal testing machine and the assumption of such parameters can be considered incorrect.

Moreover, a large spread of stresses is noticeable in the case of changing the cohesion by $20 \mathrm{kPa}$ and the friction angle by $10^{\circ}$. In the case of the Poisson's ratio, the change in its value is the most noticeable in the initial phase, in which the graph obtained in the compression test does not coincide with the model graph. The graphs show that during the selection of parameters, it is necessary to pay special attention to the internal friction angle - in the case of changing the angle by $10^{\circ}$, we obtain stresses in the range from $0.27 \mathrm{MPa}$ to $0.46 \mathrm{MPa}$, which gives a difference of $40 \%$.

\subsection{Drucker - Prager Hypothesis}

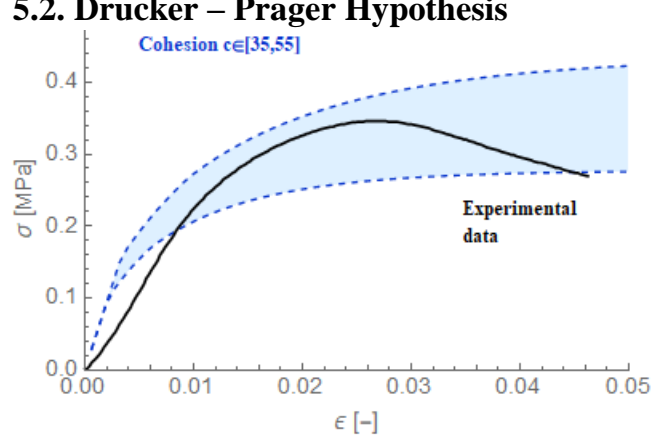

Fig. 15. Iteration envelope of the soil cohesion.

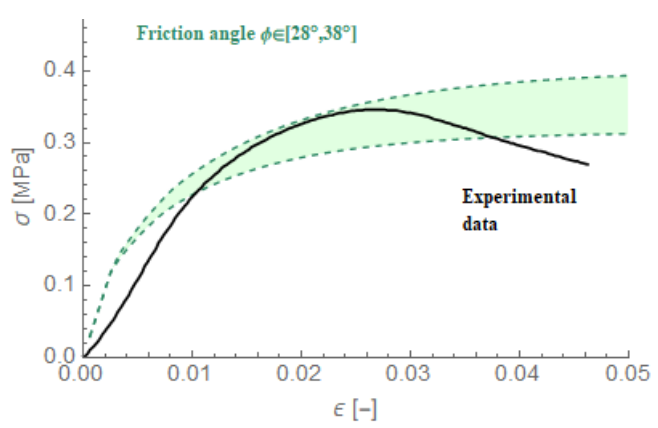

Fig. 16. Iteration envelope of the internal friction angle of the soil.

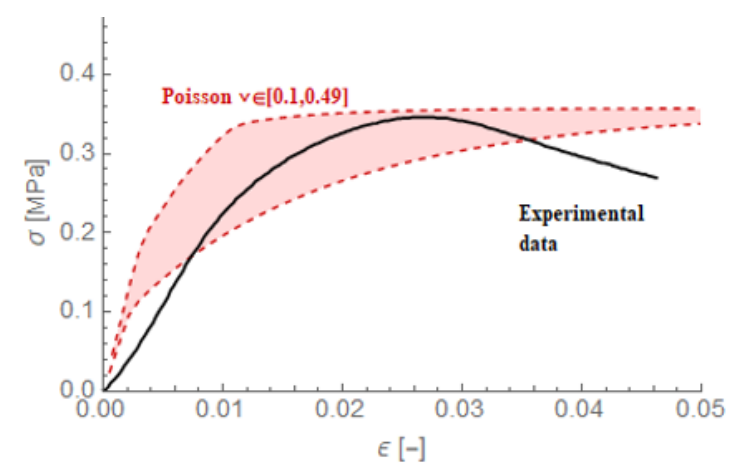

Fig. 17. Iteration envelope of the soil Poisson's ratio.

Similarly as in the case of Coulomb - Mohr analysis, the values assumed in calculations according to the Drucker - Prager criterion proved to be sufficient and the stress graphs of real sample are within the range of the model. In this case, much higher values of parameters $\mathrm{c}$ and $\phi$ were assumed than in the previous analysis. The differences amount to $13 \mathrm{kPa}$ and $7^{\circ}$, respectively, while the Poisson's ratio was the same for both criteria. Figure 15 allows to conclude that assumption of cohesion even above $45 \mathrm{kPa}$, with the angle of $33^{\circ}$, seems to be right. 
In the case of iteration of the friction angle, it can be noticed that the change of value in the range of $10^{\circ}$ does not provide as large discrepancies as in the case of the first analysis. As for the Poisson's ration, its correct assumption has certainly a big impact in the initial phase of the sample's work. Along with the strain increase, its significance decreases. By looking at the above graphs, it can concluded that more attention should be paid to the Poisson's ratio in the case of Drucker - Prager analysis than in Coulomb - Mohr analysis.

\section{Summary and conclusions}

Application of the DSM dry technology affects the increase in the soil substrate strength. However, it is necessary to bear in mind the fact that we obtain material with parameters that are difficult to estimate. Determination of the strength can be carried out by making test batches. Nevertheless, this does not solve the problem of numerical modeling. The above article attempts to determine the parameters of soil-cement for one specific sample.

The analysis proves that it is important to consciously select the strength hypothesis, according to which we will perform calculations. It was decided to carry out analysis in accordance with the Coulomb - Mohr and Drucker - Prager hypothesis. In both cases, the ideal matching of the model to the actual graph was not obtained. The reason for this is the application of elastic - plastic models, and as it can be seen, the sample of soil-cement behaves differently. In order to obtain even better results, the authors consider the use of a more complex model, e.g. the above-mentioned Cam - Clay or Hardening Soil model. Moreover, it is necessary to take into account the fact that we assume a homogeneous material in the model, while our sample is not like that. It should also be remembered that the material encountered in the substrate is generally more heterogeneous and the conducted analysis of constitutive model can only be used as the upper estimation of parameters.

From the presented results, it can be concluded that in the case of the Coulomb - Mohr hypothesis, the change of cohesion and internal friction angle has greater impact on the obtained stresses than in the case of the Drucker - Prager hypothesis. As for the Poisson's ratio, it can be seen that in the first model, it has a large impact until the material reaches the strain at the level of approx. $2 \%$. The envelope behaves differently in the second case we observe a greater impact of the Poisson's ratio. It should be noted that in the case of the Coulomb - Mohr criterion, we assumed much worse parameters than in the case of the Drucker - Prager criterion. Therefore, it may turn out that the first hypothesis is more conservative. However, it should be remembered that it will not necessarily be safer, because it requires more attention during the selection of the cohesion value, as well as the internal angle friction value, and a small change in these values results in large changes of the value of stresses. Each parameter was changed separately - while having the assumed initial value of Poisson's ratio and internal friction angle, the cohesion was changed, etc. It is not known how the model would behave, e.g. in the case of assumption of the upper cohesion value and the minimum value of internal friction angle. One thing is certain each case must be subjected to the analysis individually, because the complexity of this issue makes it very easy to make a mistake during the attempts to categorize the parameters of soil-cement, especially in the case of high organic parts amount and when other binders or granular materials are implemented to build the composite internal strength $[18,19]$.

The authors would like to thank MENARD Polska Sp. z o.o. for providing soil material, B.U.G. GEOTECH for making available their laboratory for the preparing and storing of soil cement test samples. Our deep gratitude is addressed to the laboratory staff at the Faculty of Civil Engineering. This work was done within the internal research grant at the Wrock aw University of Science and Technology: grant no. 45WB/0001/17 - "Industrialized construction process (construction 4.0)". 


\section{References}

1. J. Forsman H. Jyrävä P. Lahtinen T. Niemelin I. Hyvönen. Mass stabilization manual. http://projektit.ramboll.fi/massastabilointi/materials/mass_stabilization_manual_2015.pdf

2. Design Guide: Soft Soil Stabilisation: EuroSoilStab: Development of Design and Construction Methods to Stabilise Soft Organic Soils, IHS BRE Press, ISBN1860815995, (2010)

3. I. Karpisz, J. Pyda, L. Cichy, D. Sobala, Study of the effect of cement amount on the soil-cement sample strength, IOP Conf. Ser.: Mater. Sci. Eng., 365, 042061 (2018)

4. I. Karpisz, K. Jaworski, Study of compressive strength evolution in soil cement samples with fly-ash admixtures, IOP Conf. Ser.: Mater. Sci. Eng., 365, 032049 (2018)

5. K. Jendrysik, M. Kiecana, H. Szabowicz, Preliminary results of dry Deep Soil Mixing soil-cement composite testing, MATEC Web Conf., 251, 01025 (2018)

6. M. Kiecana, P. Kanty, K. Łużyńska, Optimal control time evaluation for "dry DSM" soil-cement composites, MATEC Web Conf., 251, 01023 (2018)

7. A. Leśniewska, Strength and technological issues of soil improvement by means of Deep Soil Mixing Wet technology. Doctor's Thesis, Gdańsk University of Science and Technology, (in Polish), (2007)

8. M. Topolnicki, Design and execution practice of wet Soil Mixing in Poland, International Symposium on Deep Mixing \& Admixture Stabilization, Okinawa, 19-21 May, 195-202 (2009)

9. D. Stefaniuk, P. Zajączkowski, J. Rybak, Methodology of axial testing of cement-fly ash-soil samples. Stroitel'stvo-formirovanie sredy žiznedeâtel'nosti. Moskva, 27-29 aprilâ 2016 r. : sbornik materialov. Moskva : NIU MGSU, 1091-94, (2016)

10. P. Kanty, J. Rybak, D. Stefaniuk, Some remarks on practical aspects of laboratory testing of deep soil mixing composites achieved in organic soils, IOP Conf. Ser.: Mater. Sci. Eng., 245 (2), 022018 (2017)

11. A.A. Egorova, J. Rybak, D. Stefaniuk, P. Zajączkowski, Basic aspects of deep soil mixing technology control, IOP Conf. Ser.: Mater. Sci. Eng., 245 (2), 022019 (2017)

12. J.L. Chaumeny, P. Kanty, T. Reitmeier, Remarks on wet deep soil mixing quality control, XVI Danube - European Conf. on Geotechnical Engineering, 07-09 June 2018, Skopje, R. Macedonia, 039, (2018)

13. K. Brasse, T. Tracz, T. Zdeb, P. Rychlewski, Influence of Soil-Cement Composition on its Selected Properties. MATEC Web Conf., 163, 06006 (2018)

14. M. Drusa, V. Chebeň, R. Bulko, New technologies implemented in geotechnical monitoring on transport constructions. Int. Multidisciplinary Scientific GeoConference Surveying Geology and Mining Ecology Management, SGEM, 2, 651-56 (2014)

15. P. Rychlewski, Wzmacnianie podłoża gruntowego pod inwestycje infrastrukturalne, Materiały budowlane, 547 (3/2018), 6-8 (2018) [in Polish]

16. B. Kliszczewicz, Interakcja podziemnych rurociągów o różnych sztywnościach $\mathrm{z}$ gruntem. Autoreferat dotyczacy osiagnięcia naukowego, stanowiacego przedmiot postępowania habilitacyjnego oraz działalności naukowo - badawczej, zawodowej, dydaktycznej i organizacyjnej. Politechnika Śląska [in Polish] (2014)

17. M. Cudny, K. Binder, Shear strength criteria for soils in geotechnical problems, Inżynieria Morska i Geotechnika, 6, 456-465 (2005)

18. J. Kawalec, S. Kwiecień, A. Pilipenko, J. Rybak, Application of crushed concrete in geotechnical engineering - selected issues, Conf. Ser.: Earth Environ. Sci., 95 (2), 022057 (2017)

19. A. Pilipenko, S. Bazhenova, Usage of crushed concrete fines in decorative concrete, IOP Conf. Ser.: Mater. Sci. Eng., 245 (2), 032082 (2017) 